\title{
Colonialidad del PODER Y CLASIFICACIÓN SOCIAL*
}

\section{INTRODUCCIón}

La colonialidad es uno de los elementos constitutivos y específicos del patrón mundial de poder capitalista. Se funda en la imposición de una clasificación racial / étnica de la población del mundo como piedra angular de dicho patrón de poder, y opera en cada uno de los planos, ámbitos y dimensiones, materiales y subjetivas, de la existencia cotidiana y a escala

\footnotetext{
* Castro-Gómez, Santiago y Grosfoguel, Ramón (comps.) 2007 El giro decolonial: reflexiones para una diversidad epistémica más allá del capitalismo global (Bogotá: Siglo del Hombre / Universidad Central / Instituto de Estudios Sociales Contemporáneos y Pontificia Universidad Javeriana / Instituto Pensar). Primera edición en Giovanni Arrighi and Walter L. Goldfrank (eds.) 2000 Festschrift For Immanuel Wallerstein en Journal of World Systems Research (Colorado) Vol. VI, no. 2, Fall/Winter, pp.342-388. Special Issue.
}

social $^{1}$. Se origina y mundializa a partir de Amé-

1 Colonialidad es un concepto diferente, aunque vinculado con el concepto de colonialismo. Este último se refiere estrictamente a una estructura de dominación y explotación, donde el control de la autoridad política, de los recursos de producción y del trabajo de una población determinada lo detenta otra de diferente identidad, y cuyas sedes centrales están, además, en otra jurisdicción territorial. Pero no siempre, ni necesariamente, implica relaciones racistas de poder. El colonialismo es, obviamente, más antiguo, en tanto que la colonialidad ha probado ser, en los últimos quinientos años, más profunda y duradera que el colonialismo. Pero sin duda fue engendrada dentro de éste y, más aún, sin él no habría podido ser impuesta en la intersubjetividad del mundo, de modo tan enraizado y prolongado. Pablo González Casanova (1965) y Rodolfo Stavenhagen (1965) propusieron llamar "colonialismo interno" al poder racista / etnicista que opera dentro de un Estado-nación. Pero eso tendría sentido sólo desde una perspectiva eurocéntrica sobre el Estado-nación. Sobre mis propuestas acerca del concepto de colonialidad del poder, remito, sobre todo, a 
rica. Con la constitución de América (Latina) ${ }^{2}$, en el mismo momento y en el mismo movimiento histórico, el emergente poder capitalista se hace mundial, sus centros hegemónicos se localizan en las zonas situadas sobre el Atlántico -que después se identificarán como Europa-, y como ejes centrales de su nuevo patrón de dominación se establecen también la colonialidad y la modernidad. En otras palabras: con América (Latina) el capitalismo se hace mundial, eurocentrado y la colonialidad y la modernidad se instalan, hasta hoy, como los ejes constitutivos de este específico patrón de poder ${ }^{3}$.

En el curso del despliegue de esas características del poder actual, se fueron configurando las nuevas identidades sociales de la colo-

mis textos (1991: 11-29; 1993 y 1994). Véase, también, mi texto escrito junto con Immanuel Wallerstein: "Americanity as a Concept or the Americas in the Modern World System" (1992).

2 La apropiación del nombre "América" por Estados Unidos ha originado una extendida confusión que aquí nos obliga a recordar que originalmente el nombre correspondía exclusivamente a los dominios ibéricos en este continente, que abarcaban desde Tierra del Fuego hasta más o menos la mitad suroeste del actual territorio de los Estados Unidos.

3 Véase "La modernidad, el capitalismo y América Latina nacen el mismo día” (1991b). nialidad (indios, negros, aceitunados, amarillos, blancos, mestizos) y las geoculturales del colonialismo (América, África, Lejano Oriente, Cercano Oriente, Occidente y Europa). Las relaciones intersubjetivas correspondientes, en las cuales se fueron fundiendo las experiencias del colonialismo y de la colonialidad con las necesidades del capitalismo, se fueron configurando como un nuevo universo de relaciones intersubjetivas de dominación bajo la hegemonía eurocentrada. Ese específico universo es el que será después denominado modernidad.

Desde el siglo XVII, en los principales centros hegemónicos de ese patrón mundial de poder -en esa centuria no por acaso Holanda (Descartes, Spinoza) e Inglaterra (Locke, Newton)-, desde ese universo intersubjetivo fue elaborado y formalizado un modo de producir conocimiento que daba cuenta de las necesidades cognitivas del capitalismo: la medición, la cuantificación, la externalización (objetivación) de lo cognoscible respecto del conocedor, para el control de las relaciones de las gentes con la naturaleza, y entre aquellas respecto de ésta, en especial de la propiedad de los recursos de producción. Dentro de esa misma orientación fueron, también, ya formalmente naturalizadas las experiencias, identidades y relaciones históricas de la colonialidad y de 
la distribución geocultural del poder capitalista mundial. Ese modo de conocimiento fue, por su carácter y por su origen eurocéntrico, denominado racional; fue impuesto y admitido en el conjunto del mundo capitalista como la única racionalidad válida y como emblema de la modermidad. Las líneas matrices de esa perspectiva cognitiva se han mantenido, no obstante los cambios de sus contenidos específicos, y las críticas y los debates, a lo largo de la duración del poder mundial del capitalismo colonial y moderno. Esa es la modernidad / racionalidad que ahora está, finalmente, en crisis ${ }^{4}$.

El eurocentrismo, por lo tanto, no es la perspectiva cognitiva de los europeos exclusivamente, o sólo de los dominantes del capitalismo mundial, sino del conjunto de los educados bajo su hegemonía. Y aunque implica un componente etnocéntrico, éste no lo explica, ni es su fuente principal de sentido. Se trata de la perspectiva cognitiva producida en el largo tiempo del conjunto del mundo eurocentrado del capitalismo colonial / moderno, y que naturaliza la experiencia de las gentes en este patrón de poder. Esto es, la hace percibir como natural,

4 He discutido antes esas cuestiones en Modernidad, identidad y utopía en América Latina (1988) y en “Colonialidad y modernidad / racionalidad" (1991a). en consecuencia, como dada, no susceptible de ser cuestionada. Desde el siglo XVIII, sobre todo con el Iluminismo, en el eurocentrismo se fue afirmando la mitológica idea de que Europa era preexistente a ese patrón de poder; que ya era antes un centro mundial del capitalismo que colonizó al resto del mundo y elaboró por su cuenta y desde dentro la modernidad y la racionalidad $^{5}$. En este orden de ideas, Europa y los europeos eran el momento y el nivel más avanzados en el camino lineal, unidireccional y continuo de la especie. Se consolidó así, junto con esa idea, otro de los núcleos principales de la colonialidad / modernidad eurocéntrica: una concepción de humanidad, según la cual la población del mundo se diferencia en inferiores y superiores, irracionales y racionales, primitivos y civilizados, tradicionales y modernos. Más tarde, en especial desde mediados del siglo XIX y a pesar del continuado despliegue de la mundialización del capital, fue saliendo de la perspectiva hegemónica la percepción

5 "Europa" es aquí el nombre de una metáfora, no de una zona geográfica ni de su población. Se refiere a todo lo que se estableció como una expresión racial / étnica / cultural de Europa, como una prolongación de ella, es decir, como un carácter distintivo de la identidad no sometida a la colonialidad del poder. 
de la totalidad mundial del poder capitalista y del tiempo largo de su reproducción, cambio y crisis. El lugar del capitalismo mundial fue ocupado por el Estado-nación y las relaciones entre Estados-nación, no sólo como unidad de análisis sino como el único enfoque válido de conocimiento sobre el capitalismo; no sólo en el liberalismo sino también en el llamado materialismo histórico, la más difundida y la más eurocéntrica de las vertientes derivadas de la heterogénea herencia de Marx.

La revuelta intelectual contra esa perspectiva y contra ese modo eurocéntrico de producir conocimiento nunca estuvo exactamente ausente, en particular en América Latina ${ }^{6}$. Pero no levanta vuelo realmente sino después de la

6 Una crítica explícita al evolucionismo unilineal y unidireccional del eurocentrismo está ya presente, por ejemplo, en el libro de Haya de la Torre $E l$ Antiimperialismo y el APRA (escrito según su autor en 1924, aunque su primera edición es de 1932). La percepción de las relaciones económicas de poder en el Perú, implicada en el primero de los Ensayos de interpretación de la realidad peruana (1928) de José Carlos Mariátegui, puede ser considerada como el embrión del concepto de heterogeneidad históricoestructural, elaborado a mediados de los años sesenta. Véase mi libro Notas sobre el concepto de marginalidad social (1966).
Segunda Guerra Mundial, comenzando, por supuesto, en las áreas dominadas y dependientes del mundo capitalista. Cuando se trata del poder, es siempre desde los márgenes desde donde suele ser más visto, y más temprano, porque entra en cuestión la totalidad del campo de relaciones y de sentidos que constituye tal poder. Desde América Latina, sin duda la más influyente de las tentativas de mostrar de nuevo la mundialidad del capitalismo fue la propuesta de Raúl Prebisch y sus asociados, para pensar el capitalismo como un sistema mundial diferenciado en "centros" y "periferias". Tal visión fue retomada y reelaborada en la obra de Immanuel Wallerstein, cuya propuesta teórica del "sistema-mundo moderno", desde una perspectiva donde confluyen la visión marxiana del capitalismo como un sistema mundial y la braudeliana sobre la larga duración histórica, ha reabierto y renovado, de modo decisivo, el debate sobre la reconstitución de una perspectiva global en la investigación científico-social del último cuarto del siglo $\mathrm{XX}^{7}$. En ese nuevo con-

7 Véase, de Raúl Prebisch, Hacia una dinámica del desarrollo latinoamericano (1963), "Crítica al capitalismo periférico" (1976) y Capitalismo periférico, crisis y transformación (1981). Véase también, de Immanuel Wallerstein, The Modern World System (1974-1989). 
texto están hoy activos otros componentes del debate latinoamericano que apuntan hacia una nueva idea de totalidad histórico-social, núcleo de una racionalidad no-eurocéntrica. Me refiero a las propuestas sobre la colonialidad del poder y sobre la heterogeneidad históricoestructural de todos los mundos de existencia social, de las cuales hablaré inmediatamente.

\section{LA CUESTIÓN DEL PODER EN EL EUROCENTRISMO}

Tal como lo conocemos históricamente, el poder es un espacio y una malla de relaciones sociales de explotación / dominación / conflicto articuladas, básicamente, en función y en torno de la disputa por el control de los siguientes ámbitos de existencia social: 1) el trabajo y sus productos; 2) en dependencia del anterior, la "naturaleza" y sus recursos de producción; 3) el sexo, sus productos y la reproducción de la especie; 4) la subjetividad y sus productos materiales e intersubjetivos, incluido el conocimiento; 5) la autoridad y sus instrumentos, de coerción en particular, para asegurar la reproducción de ese patrón de relaciones sociales y regular sus cambios. En las dos últimas centurias, sin embargo, y hasta la irrupción de las cuestiones de subjetividad y de género en el debate, la mirada eurocéntrica no ha podido percibir todos esos ámbitos en la configuración del poder, porque ha sido dominada por la confrontación entre dos principales vertientes de ideas: una hegemónica: el liberalismo; y otra subalterna, aunque de intención contestataria: el materialismo histórico.

El liberalismo no tiene una perspectiva unívoca sobre el poder. Su más antigua variante (Hobbes) sostiene que es la autoridad, acordada por individuos hasta entonces dispersos, lo que ubica los componentes de la existencia social en un orden adecuado a las necesidades de la vida individual. Aunque de nuevo actual, como sustento del neoliberalismo, durante gran parte del siglo XX cedió terreno a la predominancia de las propuestas del estructuralismo, del estructural-funcionalismo y del funcionalismo, cuyo elemento común respecto del problema es que la sociedad se ordena en torno de un limitado conjunto de patrones históricamente invariantes, por lo cual los componentes de una sociedad guardan entre sí relaciones continuas y consistentes, en razón de sus respectivas funciones, y éstas, a su vez, son inherentes al carácter de cada elemento. Con todas esas variantes, hoy coexisten y se combinan de muchos modos el viejo empirismo y el 
nuevo posmodernismo, para los cuales no hay tal cosa como una estructura global de relaciones sociales, una sociedad, en tanto que una totalidad determinada y distinguible de otras. De esa manera se dan la mano con la antigua propuesta hobbesiana.

Para el materialismo histórico -la más eurocéntrica de las versiones de la heterogénea herencia de Marx-, las estructuras sociales se constituyen sobre la base de las relaciones que se establecen para el control del trabajo y de sus productos. Tales relaciones se denominan relaciones de producción. Pero, a diferencia de las variantes del liberalismo, no sólo afirma la primacía de uno de los ámbitos -el trabajo y las relaciones de producción- sobre los demás, sino también, y con idéntica insistencia, que el orden configurado corresponde a una cadena de determinaciones que proviene del ámbito primado y atraviesa al conjunto. Desde ese punto de vista, el control del trabajo es la base sobre la cual se articulan las relaciones de poder $\mathrm{y}$, a la vez, el determinante del conjunto y de cada una de ellas. A pesar de sus muchas y muy marcadas diferencias, en todas esas vertientes se puede discernir un conjunto de supuestos y de problemas comunes que indican su común linaje eurocéntrico. Aquí es pertinente poner de relieve, principalmente, dos cuestiones. En primer término, todas presuponen una estructura configurada por elementos históricamente homogéneos, no obstante la diversidad de formas y caracteres, que guardan entre sí relaciones continuas y consistentes sea por sus "funciones", sea por sus cadenas de determinaciones-, lineales y unidireccionales, en el tiempo y en el espacio.

Toda estructura social es, en esa perspectiva, orgánica o sistémica, mecánica. Y esa es, exactamente, la opción preferencial del eurocentrismo en la producción del conocimiento histórico. En esa opción, algo llamado "sociedad”, en tanto que una articulación de múltiples existencias en una única estructura, o no es posible y no tiene lugar en la realidad, como en el viejo empirismo y en el nuevo posmodernismo, o si existe sólo puede ser de modo sistémico u orgánico. En segundo lugar, en todas esas vertientes subyace la idea de que de algún modo las relaciones entre los componentes de una estructura social son dadas, ahistóricas, esto es, son el producto de la actuación de algún agente anterior a la historia de las relaciones entre las gentes. Si, como en Hobbes, se hacen intervenir acciones y decisiones humanas en el origen de la autoridad y del orden, no se trata en rigor de ninguna historia, o siquiera de un mito histórico, sino de un mito metafísico que postula un 
estado de naturaleza, con individuos humanos que entre sí no guardan relaciones distintas a la continua violencia, es decir, que no tienen entre sí genuinas relaciones sociales. Si en Marx también se hacen intervenir acciones humanas en el origen de las "relaciones de producción", para el materialismo histórico eso ocurre por fuera de toda subjetividad, esto es, también metafísica y no históricamente. No de modo distinto, en el funcionalismo, en el estructuralismo y en el estructural-funcionalismo, las gentes están sometidas $a b$ initio al imperio de ciertos patrones de conducta históricamente invariantes.

La perspectiva eurocéntrica, en cualquiera de sus variantes, implica, pues, un postulado históricamente imposible: que las relaciones entre los elementos de un patrón histórico de poder tienen ya determinadas sus relaciones antes de toda historia. Esto es, como si fueran relaciones definidas previamente en un reino óntico, ahistórico o transhistórico. La modernidad eurocéntrica no parece haber terminado con el ejercicio de secularizar la idea de un Dios providencial. De otro modo, concebir la existencia social de gentes concretas como configurada $a b$ initio y por elementos históricamente homogéneos y consistentes, destinados indefinidamente a guardar entre sí rela- ciones continuas, lineales y unidireccionales, sería innecesario y a fin de cuentas impensable.

\section{LA HETEROGENEIDAD HISTÓRICO- ESTRUCTURAL DEL PODER}

Semejante perspectiva de conocimiento difícilmente podría dar cuenta de la experiencia histórica. En primer término, no se conoce patrón alguno de poder en el cual sus componentes se relacionen de ese modo y en especial en el largo tiempo. Lejos de eso, se trata siempre de una articulación estructural entre elementos históricamente heterogéneos, es decir, que provienen de historias específicas y de espaciostiempos distintos y distantes entre sí, que de ese modo tienen formas y caracteres no sólo diferentes, sino discontinuos, incoherentes y aun conflictivos entre sí, en cada momento y en el largo tiempo. De ello son una demostración histórica eficiente, mejor quizás que ninguna otra experiencia, precisamente la constitución y el desenvolvimiento histórico de América y del capitalismo mundial, colonial y moderno.

En cada uno de los principales ámbitos de la existencia social, cuyo control disputan las gentes, y de cuyas victorias y derrotas se forman las relaciones de explotación / domina- 
ción / conflicto que constituyen el poder, los elementos componentes son siempre históricamente heterogéneos. Así, en el capitalismo mundial el trabajo existe actualmente, como hace quinientos años, en todas y cada una de sus formas históricamente conocidas (salario, esclavitud, servidumbre, pequeña producción mercantil, reciprocidad), pero todas ellas al servicio del capital y articulándose en torno de su forma salarial. Pero, del mismo modo, en cualquiera de los otros ámbitos -la autoridad, el sexo, la subjetividad- están presentes todas las formas históricamente conocidas, bajo la primacía general de sus formas llamadas modernas: el "Estado-nación", "la familia burguesa", la "racionalidad moderna".

Lo que es realmente notable de toda estructura social es que elementos, experiencias, productos, históricamente discontinuos, distintos, distantes y heterogéneos puedan articularse juntos, no obstante sus incongruencias y sus conflictos, en la trama común que los urde en una estructura conjunta. La pregunta pertinente indaga acerca de lo que produce, permite o determina semejante campo de relaciones, y le otorga el carácter y el comportamiento de una totalidad histórica específica y determinada. Y como la experiencia de América y del actual mundo capitalista lo demuestra, en cada caso lo que en primera instancia genera las condiciones para esa articulación es la capacidad que un grupo logra obtener o encontrar para imponerse sobre los demás y articular bajo su control, en una nueva estructura social, sus heterogéneas historias. Es siempre una historia de necesidades, pero igualmente de intenciones, de deseos, de conocimientos o ignorancias, de opciones y preferencias, de decisiones certeras o erróneas, de victorias y derrotas. De ningún modo, en consecuencia, de la acción de factores extrahistóricos.

Las posibilidades de acción de las gentes no son infinitas, o siquiera muy numerosas y diversas. Los recursos que disputan no son abundantes. Más significativo aún es el hecho de que las acciones $\mathrm{u}$ omisiones humanas no pueden desprenderse de lo que está ya previamente hecho y existe como condicionante de las acciones, externamente o no de la subjetividad, del conocimiento y/o de los deseos y de las intenciones. Por ello, las opciones, queridas o no, conscientes o no, para todos o para algunos, no pueden ser decididas, ni actuadas, en un $v a$ cuum histórico. De allí no se deriva, sin embargo, no necesariamente en todo caso, que las opciones estén inscritas ya en una determinación extrahistórica, suprahistórica o transhistórica, como en el destino de la tragedia griega clási- 
ca. No son, en suma, inevitables. ¿O lo era el hecho de que Colón tropezara con lo que llamó La Hispaniola en lugar de llegar a lo que hoy llamamos Nueva York? Las condiciones técnicas de esa aventura permitían lo mismo el uno que el otro resultado, o el fracaso de ambos. Piénsese en todas las implicaciones fundamentales, no banales, de tal cuestión, para la historia del mundo capitalista.

La capacidad y la fuerza que le sirven a un grupo para imponerse sobre otros no es, sin embargo, suficiente para articular heterogéneas historias en un orden estructural duradero. Ellas ciertamente producen la autoridad, en tanto que capacidad de coerción. La fuerza y la coerción, o, en la mirada liberal, el consenso, no pueden, sin embargo, producir, ni reproducir duraderamente el orden estructural de una sociedad, es decir, las relaciones entre los componentes de cada uno de los ámbitos de la existencia social, ni las relaciones entre los ámbitos mismos. Ni, en especial, producir el sentido del movimiento y del desenvolvimiento histórico de la estructura social en su conjunto. Lo único que puede hacer la autoridad es obligar, o persuadir, a las gentes a someterse a esas relaciones y a ese sentido general del movimiento de la sociedad que les habita. De ese modo contribuye al sostenimiento, a la repro- ducción de esas relaciones y al control de sus crisis y de sus cambios.

Si desde Hobbes el liberalismo insiste, sin embargo, en que la autoridad decide el orden social, el orden estructural de las relaciones de poder, es porque también insiste en que todos los otros ámbitos de existencia social articulados en esa estructura son naturales. Pero si no se admite ese imposible carácter no-histórico de la existencia social, debe buscarse en otra instancia histórica la explicación de que la existencia social consista en ámbitos o campos de relaciones sociales específicas, y que tales campos tiendan a articularse en un campo conjunto de relaciones, cuya configuración estructural y su reproducción o remoción en el tiempo se reconoce con el concepto de sociedad. ¿Dónde encontrar esa instancia? Ya quedó señalada la dificultad de las propuestas estructuralistas y funcionalistas, no sólo para dar cuenta de la heterogeneidad histórica de las estructuras sociales, sino también por implicar relaciones necesariamente consistentes entre sus componentes. Queda, en consecuencia, la propuesta marxiana (una de las fuentes del materialismo histórico) sobre el trabajo como ámbito primado de toda sociedad, y sobre el control del trabajo como el primado en todo poder social. Dos son los 
problemas que levanta esta propuesta y que requieren ser discutidos.

En primer lugar, es cierto que la experiencia del poder capitalista mundial, eurocentrado y colonial / moderno, muestra que es el control del trabajo el factor primado en este patrón de poder: éste es, en primer término, capitalista. En consecuencia, el control del trabajo por el capital es la condición central del poder capitalista. Pero en Marx implica, de una parte, la homogeneidad histórica de éste y de los demás factores, y de otra parte, que el trabajo determina, todo el tiempo y de modo permanente, el carácter, el lugar y la función de todos los demás ámbitos en la estructura de poder. Sin embargo, si se examina de nuevo la experiencia del patrón mundial del poder capitalista, nada permite verificar la homogeneidad histórica de sus componentes, ni siquiera de los fundamentales, sea del trabajo, del capital, o del capitalismo. Por el contrario, dentro de cada una de esas categorías no sólo coexisten, sino se articulan y se combinan todas y cada una de las formas, etapas y niveles de la historia de cada una de ellas. Por ejemplo, el trabajo asalariado existe hoy, como al comienzo de su historia, junto con la esclavitud, la servidumbre, la pequeña producción mercantil, la reciprocidad. Y to- dos ellos se articulan entre sí y con el capital. El propio trabajo asalariado se diferencia entre todas las formas históricas de acumulación, desde la llamada originaria o primitiva, la plusvalía extensiva, incluyendo todas las gradaciones de la intensiva y todos los niveles que la actual tecnología permite y contiene, hasta aquellos en que la fuerza viva de trabajo individual es virtualmente insignificante. El capitalismo abarca, tiene que abarcar, todo ese complejo y heterogéneo universo bajo su dominación.

Respecto de la cadena unidireccional de determinaciones que le permite al trabajo articular los demás ámbitos y mantenerlos articulados en el largo tiempo, la experiencia del patrón de poder capitalista, mundial, eurocentrado y colonial / moderno no muestra tampoco nada que obligue a admitir que el rasgo capitalista haya hecho necesarios, en el sentido de inevitables, los demás. De otra parte, sin duda el carácter capitalista de este patrón de poder tiene implicaciones decisivas sobre el carácter y el sentido de las relaciones intersubjetivas, de las relaciones de autoridad y sobre las relaciones en torno del sexo y sus productos. Pero, primero, sólo si se ignora la heterogeneidad histórica de esas relaciones y del modo como se ordenan en cada ámbito 
y entre ellos, sería posible admitir la unilinealidad y unidireccionalidad de esas implicaciones. Y, segundo, a esta altura del debate debiera ser obvio que si bien el actual modo de controlar el trabajo tiene implicaciones sobre, por ejemplo, la intersubjetividad social, sabemos, del mismo modo, que para que se optara por la forma capitalista de organizar y controlar el trabajo, fue necesaria una intersubjetividad que la hiciera posible y preferible. Las determinaciones no son, pues, no pueden ser, unilineales, ni unidireccionales. Y no sólo son recíprocas. Son heterogéneas, discontinuas, inconsistentes, conflictivas, como corresponde a las relaciones entre elementos que tienen, todos y cada uno, tales características. La articulación de heterogéneos, discontinuos y conflictivos elementos en una estructura común, en un determinado campo de relaciones, implica, pues, requiere, relaciones de recíprocas, múltiples y heterogéneas determinaciones.

El estructuralismo y el funcionalismo no lograron percibir esas necesidades históricas. Tomaron un camino mal-conducente, reduciéndolas a la idea de relaciones funcionales entre los elementos de una estructura social. De todos modos, sin embargo, para que una estructura histórico-estructuralmente hete- rogénea tenga el movimiento, el desenvolvimiento o, si se quiere, el comportamiento de una totalidad histórica, no bastan tales modos de determinación recíproca y heterogénea entre sus componentes. Es indispensable que uno (o más) entre ellos tenga la primacía -en el caso del capitalismo, el control combinado del trabajo y de la autoridad- pero no como determinante o base de determinaciones en el sentido del materialismo histórico, sino estrictamente como eje(s) de articulación del conjunto. De ese modo, el movimiento conjunto de esa totalidad, el sentido de su desenvolvimiento, abarca, trasciende cada uno de sus componentes. Es decir, determinado campo de relaciones sociales se comporta como una totalidad. Pero semejante totalidad histórico-social, como articulación de heterogéneos, discontinuos y conflictivos elementos, no puede ser de modo alguno cerrada, no puede ser un organismo, ni puede ser, como una máquina, consistente de modo sistémico, y constituir una entidad en la cual la lógica de cada uno de los elementos corresponde a la de cada uno de los otros. Sus movimientos de conjunto no pueden ser, en consecuencia, unilineales, ni unidireccionales, como sería necesariamente el caso de entidades orgánicas o sistémicas o mecánicas. 


\section{NOTAS SOBRE LA CUESTIÓN DE LA TOTALIDAD}

Acerca de esa problemática es indispensable continuar indagando y debatiendo las implicaciones del paradigma epistemológico de la relación entre el todo y las partes respecto de la existencia histórico-social. El eurocentrismo ha llevado, a virtualmente todo el mundo, a admitir que en una totalidad el todo tiene absoluta primacía determinante sobre todas y cada una de las partes, y que por lo tanto hay una y sólo una lógica que gobierna el comportamiento del todo y de todas y de cada una de las partes. Las posibles variantes en el movimiento de cada parte son secundarias, sin efecto sobre el todo, y reconocidas como particularidades de una regla o lógica general del todo al que pertenecen. No es pertinente aquí, por razones obvias, plantear un debate sistemático acerca de aquel paradigma que en la modernidad eurocéntrica ha terminado siendo admitido como una de las piedras angulares de la racionalidad, y que en la producción del conocimiento concreto llega a ser actuado con la espontaneidad de la respiración, esto es, de manera incuestionable. Lo único que propongo aquí es abrir la cuestión restricta de sus implicaciones en el conocimiento específico de la experiencia histórico-social. En la partida, es necesario reconocer que todo fenómeno histórico-social consiste en y/o expresa una relación social o una malla de relaciones sociales. Por eso, su explicación y su sentido no pueden ser encontrados sino respecto de un campo de relaciones mayor al que corresponde. Dicho campo de relaciones respecto del cual un determinado fenómeno puede tener explicación y sentido es lo que aquí se asume con el concepto de totalidad histórico-social. La continuada presencia de este paradigma en la investigación y en el debate histórico-social desde, sobre todo, fines del siglo XVIII, no es un accidente: da cuenta del reconocimiento de su tremenda importancia, ante todo porque permitió liberarse del atomismo empirista y del providencialismo. No obstante, el empirismo atomístico no sólo se ha mantenido en el debate, sino que ahora ha encontrado una expresión nueva en el llamado posmodernismo filosófico-social ${ }^{8}$. En ambos se

8 El término "filosófico-social" cumple aquí la función de hacer notar que el intenso proceso de renovación del debate filosófico tiene un sello peculiar: no se trata sólo de una prolongación del viejo debate sobre las viejas cuestiones de la metafísica eurocéntrica, sino de las cuestiones levantadas en el debate histórico-social de los últimos doscientos años, y en particular en la segunda mitad del siglo XX. El reconocimiento de este rasgo 
niega la idea de totalidad y de su necesidad en la producción del conocimiento.

La renovación y la expansión de la visión atomística de la experiencia histórico-social en plena crisis de la modernidad / racionalidad no es tampoco un accidente. Es un asunto complejo y contradictorio. Da cuenta, por un lado, de que ahora es más perceptible que las ideas dominantes de totalidad dejan fuera de ellas muchas, demasiadas, áreas de la experiencia histórico-social, o las acogen sólo de modo distorsionante. Pero, por otro lado, tampoco es accidental la explícita asociación de la negación de la totalidad con la negación de la realidad del poder social, en el nuevo posmodernismo tanto como en el viejo empirismo.

En efecto, lo que el paradigma de la totalidad permitió percibir en la historia de la existencia social de las gentes concretas fue, precisamente, el poder como la más persistente forma de articulación estructural de alcance social. Desde entonces, sea para ponerlo en

es importante para nosotros, no sólo y no tanto porque indica la influencia de las ciencias sociales sobre la filosofía, sino ante todo porque este debate es vital para la elaboración de una racionalidad alternativa a la eurocéntrica y para la renovación de los fundamentos del conocimiento histórico-social. cuestión o para su defensa, el punto de partida ha sido el reconocimiento de su existencia real en la vida de las gentes. Pero, sobre todo, fue la crítica del poder la que terminó colocada en el centro mismo del estudio y del debate histórico-social. En cambio, en la visión atomística, sea del viejo empirismo o del nuevo posmodernismo, las relaciones sociales no forman campos complejos de relaciones sociales en donde están articulados todos los ámbitos diferenciables de existencia social y, en consecuencia, de relaciones sociales. Es decir, algo llamado "sociedad" no tiene lugar en la realidad. Por lo tanto, encontrar la explicación y el sentido de los fenómenos sociales no es posible, ni necesario. La experiencia contingente, la descripción como representación, serían lo único necesario y legítimo. La idea de totalidad no sólo no sería necesaria sino, sobre todo, sería una distorsión epistemológica. La idea que remite a la existencia de estructuras duraderas de relaciones sociales cede el lugar a la idea de fluencias inestables y cambiantes, que no llegan a cuajar en estructuras ${ }^{9}$.

Para poder negar la realidad del poder social, el empirismo y el posmodernismo requie-

9 Véase Roland Anrup (1985: 5-23). 
ren negar la idea de totalidad histórico-social y la existencia de un ámbito primado en la configuración social, actuando como eje de articulación de los demás. El poder en el viejo empirismo sólo existe como autoridad, en un solo ámbito de relaciones sociales, por definición, dispersas. En el posmodernismo, desde sus orígenes post-estructuralistas, el poder sólo existe a la escala de las micro-relaciones sociales y como fenómeno disperso y fluido. No tiene sentido, en consecuencia, para ninguna de tales vertientes del debate, pensar en el cambio de algo llamado "sociedad" en su conjunto y ubicar para eso sus ejes de articulación o los factores de determinación que deben ser cambiados. El cambio histórico sería estrictamente un asunto individual, aunque fueran varios los individuos comprometidos en las micro-relaciones sociales.

En esa confrontación entre las ideas orgánicas y sistémicas de totalidad, de un lado, y la negación de toda idea de totalidad, del otro, pareciera tratarse de opciones muy contrapuestas, incluso referidas a perspectivas epistémicas no conciliables. Ambas tienen, sin embargo, un común linaje eurocéntrico: para ambas posiciones el paradigma eurocéntrico de totalidad es el único pensable. Dicho de otro modo, en ambas subyace el supuesto nunca explici- tado y discutido, de que toda idea de totalidad implica que el todo y las partes corresponden a una misma lógica de existencia. Es decir, tienen una homogeneidad básica que sustenta la consistencia y la continuidad de sus relaciones, como en un organismo, o en una máquina, o en una entidad sistémica. En esa perspectiva, la negación de la necesidad de esa idea de totalidad en la producción del conocimiento es extrema, pero no del todo arbitraria. Para nuestras actuales necesidades de conocimiento histórico-social, esa idea de totalidad implica hoy distorsiones de la realidad tan graves como las desventajas del viejo empirismo atomístico.

Pero, ¿qué pasa si nos enfrentamos a totalidades que consisten en una articulación de elementos históricamente heterogéneos, cuyas relaciones son discontinuas, inconsistentes, conflictivas? La respuesta es que en la existencia social las relaciones entre el todo y las partes son reales, pero necesariamente muy distintas de las que postula el eurocentrismo. Una totalidad histórico-social es en un campo de relaciones estructurado por la articulación heterogénea y discontinua de diversos ámbitos de existencia social, cada uno de ellos a su vez estructurado con elementos históricamente heterogéneos, discontinuos en el tiempo y conflictivos. Eso quiere decir que las partes 
en un campo de relaciones de poder social no son sólo "partes"; lo son respecto del conjunto del campo, de la totalidad que éste constituye y, en consecuencia, se mueve dentro de la orientación general del conjunto; pero no lo son en su relación separada con cada una de las otras. Cada una de ellas es una unidad total en su propia configuración, porque igualmente tiene una constitución históricamente heterogénea. Cada elemento de una totalidad histórica es una particularidad y, al mismo tiempo, una especificidad, incluso, eventualmente, una singularidad. Todos ellos se mueven dentro de la tendencia general del conjunto, pero tienen o pueden tener una autonomía relativa y que puede ser, o llegar a ser, conflictiva con la del conjunto. En ello reside también la noción del cambio histórico-social.

¿Significa eso que la idea de totalidad no tiene allí lugar ni sentido? Nada de eso. Lo que articula todos los ámbitos heterogéneos y discontinuos en una estructura histórico-social es un eje común, por lo cual el todo tiende a moverse, en general, de modo conjunto, actúa como una totalidad. Pero esa estructura no es, no puede ser, cerrada, como en cambio no puede dejar de serlo una estructura orgánica o sistémica. Por eso, a diferencia de éstas, si bien ese conjunto tiende a moverse o a comportarse en una orientación general, no puede hacerlo de manera unilineal, ni unidireccional, ni unidimensional, porque están en acción múltiples, heterogéneas e incluso conflictivas pulsiones o lógicas de movimiento. En especial, si se considera que son necesidades, deseos, intenciones, opciones, decisiones y acciones humanas las que están, constantemente, en juego. En otros términos, los procesos históricos de cambio no consisten, no pueden consistir, en la transformación de una totalidad históricamente homogénea en otra equivalente, sea gradual y continuamente, o por saltos y rupturas. Si así fuera, el cambio implicaría la salida completa del escenario histórico de una totalidad con todos sus componentes, para que otra derivada de ella ocupara su lugar. Esa es la idea central, necesaria, explícita en el evolucionismo gradual y unilineal, o implicada en las variantes del estructuralismo y del funcionalismo y, aunque algo en contra de su discurso formal, también del materialismo histórico. Así no ocurre, sin embargo, en la experiencia real, menos con el patrón de poder mundial que se constituyó con América. El cambio afecta de modo heterogéneo, discontinuo, a los componentes de un campo histórico de relaciones sociales. Ese es, probablemente, el significado histórico, concreto, de lo que se postula como 
contradicción en el movimiento histórico de la existencia social.

La percepción de que un campo de relaciones sociales está constituido de elementos homogéneos, continuos, aunque contradictorios (en el sentido hegeliano), lleva a la visión de la historia como una secuencia de cambios que consisten en la transformación de un conjunto homogéneo y continuo en otro equivalente. $\mathrm{Y}$ el debate sobre si eso ocurre gradual y linealmente o por "saltos", y que suele pasar como una confrontación epistemológica entre el "positivismo" y la "dialéctica" es, en consecuencia, meramente formal. No implica en realidad ninguna ruptura epistemológica. Puede verse, así, que lo que lleva a muchos a desprenderse de toda idea de totalidad es que las ideas sistémicas u orgánicas acerca de ella han llegado a ser percibidas, o sentidas, como una suerte de corsé intelectual, porque fuerzan a homogenizar la experiencia real, y de ese modo a verla de modo distorsionado. Eso no lleva a negar, desde luego, la existencia posible o probada de totalidades orgánicas o sistémicas. De hecho hay organismos y mecanos cuyas partes se corresponden unas con otras de manera sistémica. Pero toda pretensión de ver de esta manera las estructuras sociales es necesariamente distorsionante.
Desde una perspectiva orgánica o sistémica de la totalidad histórico-social, toda pretensión de manejo de totalidades histórico-sociales, en especial cuando se trata de planificar de ese modo el cambio, no puede dejar de conducir a experiencias que han dado en llamarse, no por acaso, totalitarias. Al mismo tiempo, sin embargo, puesto que no es inevitable que toda idea de totalidad sea sistémica, orgánica o mecánica, la simple negación de toda idea de totalidad en el conocimiento histórico-social no puede dejar de estar asociada a la negación de la realidad del poder a escala social. En realidad, desoculta el sesgo ideológico que la vincula al poder vigente.

\section{LA CUESTIÓN DE LA CLASIFICACIÓN SOCIAL}

Desde los años ochenta, en medio de la crisis mundial del poder capitalista, se hizo más pronunciada la derrota, ya tendencialmente visible, de los regímenes del despotismo burocrático, rival del capitalismo privado, de los procesos de democratización de las sociedades y Estados capitalistas de la "periferia", y también de los movimientos de los trabajadores orientados a la destrucción del capitalismo. Ese con- 
texto facilitó la salida a la luz de las corrientes, hasta ese momento más bien subterráneas, que dentro del materialismo histórico comenzaban a sentir cierto malestar con su concepción heredada acerca de las clases sociales ${ }^{10}$. El pronto resultado fue, como ocurre con frecuencia, que el niño fue arrojado junto con el agua sucia, y las clases sociales se eclipsaron en el escenario intelectual y político. Es obvio que ese resultado fue parte de la derrota mundial de los

10 El debate sobre el problema de las clases sociales está ya muy cargado de años, aunque se hizo más intenso después de la Segunda Guerra Mundial. Una incisiva revisión es la de Dale Tomich: "World of Capital / Worlds of Labor: A Global Perspective” (1997). Sin embargo, probablemente fue la conocida polémica de Ellen Meiksins Wood, A Retreat from Class: $A$ New "True" Socialism (1986), frente a Ernesto Laclau y Chantal Mouffe, Hegemony and Socialist Strategy (1985), lo que dio cuenta del momento de flexión climática mayor de la atmósfera intelectual del llamado "marxismo occidental" respecto de la cuestión de las clases sociales. Desde entonces, se extendió rápidamente el desuso del concepto, como ha ocurrido con casi todos los problemas teóricos centrales del debate precedente. Fueron simplemente sacados del debate, y las ideas y conceptos en juego entraron en desuso. Su regreso comienza, más bien rápidamente, con la crisis de hegemonía global, arrastrada por los apetitos predatorios del capital financiero y el desprestigio mundial del neoliberalismo. regímenes y movimientos que le disputaban la hegemonía mundial a los centros hegemónicos del capitalismo o se enfrentaban al capitalismo. Y facilitó la imposición del discurso neoliberal del capitalismo como una suerte de sentido común universal, que desde entonces hasta hace muy poco se hizo no sólo dominante, sino virtualmente único ${ }^{11}$. Es menos obvio, sin embargo, si fue única o principalmente para poder pasarse con comodidad al campo adversario, que muchos habituales de los predios del materialismo histórico se despojaran, después de la derrota, de una de sus armas predilectas.

Aunque esa es la acusación oída con más frecuencia, no es probable que sea la mejor encaminada. Es más probable que con la cuestión de las clases sociales, entre los cultores o seguidores del materialismo histórico, hubiera estado ocurriendo algo equivalente a lo que ocurrió con las ideas orgánica o sistémica acerca de la totalidad: las derrotas y, sobre todo, las decepciones en su propio campo político (el "socialismo realmente existente") hacían cada vez más problemático el uso productivo, en el campo del conocimiento, de la versión

11 "Pensamiento único" es el nombre acuñado y reiteradamente usado por Ignacio Ramonet en las páginas de Le Monde Diplomatique, que él dirige. 
del materialismo histórico sobre las clases sociales. Esa versión había logrado convertir una categoría histórica en una categoría estática, en los términos de E. P. Thompson, y en amplia medida ese era el producto que, según la descripción de Parkin, a fines de los setenta, se "fabricaba y mercadeaba" en muchas universidades de Europa y de Estados Unidos ${ }^{12}$. Y puesto que para una amplia mayoría, dicha versión era la única legitimada como correcta, el respectivo concepto de clases sociales comenzó a ser sentido también como un corsé intelectual. Los esfuerzos para hacer más llevadero ese corsé, si bien no fueron muy numerosos, ganaron amplia audiencia en los años sesenta. Piénsese, por ejemplo, en la resonancia de la obra de Nicos Poulantzas, en una vereda, o la de Erik Olin Wright, en la de enfrente ${ }^{13}$. Esfuerzos de crítica mucho más fecunda pero con menos audiencia inmediata, como la de E. P. Thompson, desafortunadamente no llevaron hasta una entera propuesta alternativa ${ }^{14} \cdot ¿ D e$

12 Véase Frank Parkin (1979).

13 De Nicos Poulantzas véase, en especial, Pouvoir et Classes Sociales (1968), y de Erik Olin Wright, Class, Crisis and the State (1978).

14 Véase, de E. P. Thompson, The Making of the English Working Class (1964) y Poverty and Theory (1978). dónde proceden las dificultades con la teoría de las clases sociales del materialismo histórico? El rastro más nítido conduce a una historia con tres estancias distintas. Primera, la constitución del materialismo histórico, a fines del siglo XIX, como un producto de la hibridación marxista-positivista, en el tardío Engels y en los teóricos de la socialdemocracia europea, alemana en especial, con amplias y duraderas reverberaciones entre los socialistas de todo el mundo. Segunda, la canonización de la versión llamada marxismo-leninismo, impuesta por el despotismo burocrático establecido bajo el estalinismo, desde mediados de los años veinte. Finalmente, la nueva hibridación de ese materialismo histórico con el estructuralismo francés, después de la Segunda Guerra Mundial ${ }^{15}$. El materialismo histórico, respecto de la cuestión de las clases sociales, así como en otras áreas respecto de la herencia teórica de Marx,

15 Acerca del marxismo-positivismo, véase Theodor Shanin, The Late Marx: The Russian Road (1984). De la avasalladora influencia del estructuralismo francés en el materialismo histórico después de la segunda guerra mundial, la obra de Althusser y de los althusserianos es una convincente y conocida demostración. Y de lo devastadora que llegó a ser entre algunos de ellos, seguramente un notorio ejemplo es la obra de Hindess y Hirst, Pre-Capitalist Modes of Production (1975). 
no es exactamente una ruptura, sino una continuidad parcial y distorsionada. Ese legado intelectual es reconocidamente heterogéneo, y lo es aún más su tramo final, producido, precisamente, cuando Marx puso en cuestión los núcleos eurocéntricos de su propio pensamiento, desafortunadamente sin lograr encontrar una resolución eficaz a los problemas epistémicos y teóricos implicados. Admite, pues, heterogéneas lecturas. Pero el materialismo histórico, sobre todo en su versión marxista-leninista, pretendió, no sin éxito, hacer pasar el legado de Marx como una obra sistemáticamente homogénea e imponer su propia lectura, a fin de ser admitido como el único legítimo heredero.

Es sabido que Marx dijo expresamente que no era el descubridor de las clases sociales, ni de sus luchas, pues antes de él lo habían hecho los historiadores y economistas burgueses ${ }^{16}$. Pero, aunque él, curiosamente, no la menciona, no hay duda alguna de que fue en la obra de Claude Henri de Saint-Simon y de los saintsimonianos donde fueron formulados por primera vez, mucho antes de Marx, los elementos básicos de lo que un siglo después sería conocido como la teoría de las clases sociales del mate-

16 Véase Karl Marx y Frederic Engels (1947: 71-74). rialismo histórico ${ }^{17}$. En particular en la famosa Exposition de la Doctrine, publicada en 1828 por la llamada izquierda saintsimoniana, de extendida influencia en el debate social y político, durante buena parte del siglo XIX.

No se agotan allí las notables coincidencias con el materialismo histórico respecto de la cuestión de las clases sociales. Para ser un texto escrito después de trescientos años de historia del capitalismo mundial eurocentrado y co-

17 No se puede pasar por alto la intrigante ausencia en Marx de casi toda mención del pensamiento saintsimoniano, en especial de la Exposition de la Doctrine, tanto mayor por el hecho de que usó todos los conceptos básicos y la terminología de sus obras: la lista de clases sociales antagónicas que encabeza el capítulo I de El manifiesto ya está íntegra en la Exposition (amos y esclavos, patricios y plebeyos, señores y siervos), así como clase obrera, trabajadores asalariados, proletarios. Además, no tiene que forzarse nada la Exposition para encontrar que la perspectiva entera de la relación entre clases sociales e historia, y entre la explotación de la clase obrera o proletariado y la revolución para poner punto final a todas las formas de explotación, ya están formuladas allí, antes de reaparecer para la posteridad como las claves de la teoría revolucionaria del materialismo histórico. En ese sentido, el reconocimiento hecho por Engels (Del socialismo utópico al socialismo científico) de la "genial perspicacia" de Saint-Simon, mientras lo ubica entre los "socialistas utópicos”, es tardío e interesado. 
lonial / moderno, no puede dejar de ser llamativa la ceguera absoluta de la Exposition de la Doctrine respecto de los siguientes puntos: 1) la coexistencia y la asociación, bajo el capitalismo, de todas las formas de explotación / dominación del trabajo; 2) en el mundo del capitalismo no existían solamente las clases sociales de "industriales", de un lado, y "obreros" o "proletarios", del otro, sino también las de "esclavos", "siervos", "plebeyos" y "campesinos libres"; 3) las relaciones de dominación originadas en la experiencia colonial de "europeos" o "blancos" e "indios", "negros", "amarillos" y "mestizos", implicaban profundas relaciones de poder, que en aquel periodo estaban tan estrechamente ligadas a las formas de explotación del trabajo que parecían "naturalmente" asociadas entre sí; 4) la relación capital-salario no era el único eje de poder, ni siquiera en la economía, sino que había otros ejes de poder que existían y actuaban en ámbitos que no eran solamente económicos, como la "raza", el género y la edad; 5) en consecuencia, la distribución del poder entre la población de una sociedad no provenía exclusivamente de las relaciones en torno del control del trabajo, ni se reducía a ellas.

El movimiento de la indagación de Marx sobre las clases sociales no fue probablemente ajeno al debate de los saintsimonianos. Pero junto con sus similitudes, tiene también notables diferencias que aquí apenas es pertinente señalar. En primer término, Marx se mantuvo, es verdad, hasta casi el final de su trabajo, dentro de la misma perspectiva (saintsimoniana y eurocéntrica) de una secuencia histórica unilineal y unidireccional de sociedades de clase. Sin embargo, como se sabe bien ahora, al irse familiarizando con las investigaciones históricas y con el debate político de los "populistas" rusos, se dio cuenta de que esa unidireccionalidad y esa unilinealidad dejaban fuera de la historia otras decisivas experiencias históricas. Llegó, así, a ser consciente del eurocentrismo de su perspectiva histórica, pero no dio el salto epistemológico correspondiente. El materialismo histórico posterior eligió condenar y omitir ese tramo de la indagación de Marx, y se aferró dogmáticamente a lo más eurocéntrico de su herencia.

Es cierto, por otra parte, como todo el mundo advierte, que hay una distinción perceptible entre su visión de las relaciones de clase, implicadas en su teoría sobre el capital, y la que subyace a sus estudios históricos. En esa teoría, el capital es una relación social específica de producción, cuyos dos términos fundamentales son los capitalistas y los obreros. Los primeros son quienes controlan esa relación, 
y en esa calidad, son "funcionarios" del capital. Son los dominantes de esa relación, pero lo hacen en su propio y privado beneficio. En esa calidad, son explotadores de los obreros. Desde ese punto de vista, ambos términos son las clases sociales fundamentales de $\mathrm{El} \mathrm{Capi-}$ tal. De otro lado, sin embargo, y sobre todo en su análisis de la coyuntura francesa, especialmente en El 18 Brumario de Luis Bonaparte, Marx da cuenta de varias clases sociales que, según las condiciones del conflicto políticosocial, emergen, se consolidan o se retiran de escena: burguesía comercial, burguesía industrial, proletariado, grandes terratenientes, oligarquía financiera, pequeña-burguesía, clase media, lumpemproletariado, gran burocracia. Así mismo, en Teorías de la plusvalía, advierte que Ricardo olvida enfatizar el constante crecimiento de las clases medias.

El materialismo histórico posterior, en especial en su versión marxista-leninista, ha manejado esas diferencias en la indagación marxiana, por medio de tres propuestas. La primera es que las diferencias se deben al nivel de abstracción teórica en El Capital, e histórico coyuntural en El 18 Brumario. La segunda es que esas diferencias son, además, transitorias, pues en el desenvolvimiento del capital, la sociedad tenderá de todos modos a polarizarse en las dos clases sociales fundamentales. La tercera es que la teoría de El Capital implica que se trata de una relación social, estructurada independientemente de la voluntad y de la conciencia de las gentes, y que, en consecuencia, éstas se encuentran distribuidas en ella de manera necesaria e inevitable, por una legalidad histórica que las sobrepasa. En esa visión, las clases sociales son presentadas como estructuras dadas por la naturaleza de la relación social; sus ocupantes son portadores de sus determinaciones y, por lo tanto, sus comportamientos deberían expresar dichas determinaciones estructurales.

La primera propuesta tiene confirmación en las propias palabras de Marx. Así, ya en el famoso e inconcluso capítulo sobre las clases, del Vol. III de El Capital, Marx sostiene que:

Los propietarios de simple fuerza de trabajo, los propietarios de capital y los propietarios de tierras, cuyas respectivas fuentes de ingresos son el salario, la ganancia y la renta del suelo, es decir, los obreros asalariados, los capitalistas y los terratenientes, forman las tres grandes clases de la sociedad moderna, basada en el régimen capitalista de producción (1966: 817).

Sin embargo, comprueba que ni siquiera en Inglaterra, no obstante ser la más desarro- 
llada y "clásica" de las modernas sociedades capitalistas, "se presenta en toda su pureza esta división de la sociedad en clases", ya que clases medias y estratos intermedios no dejan que sean nítidas las líneas de separación entre las clases. Pero inmediatamente advierte que eso será depurado por el desenvolvimiento de la ley del desarrollo capitalista, que lleva continuamente a la polarización entre las clases fundamentales.

Con El 18 Brumario, sin embargo, ocurre un doble desplazamiento de problemática y de perspectiva, que no se puede explicar solamente porque se trate de un análisis histórico coyuntural. En el movimiento de la reflexión marxiana están implícitas, de una parte, la idea de que en la sociedad francesa de ese tiempo no existe sólo el salario, sino varias y diversas otras formas de explotación del trabajo, todas articuladas al dominio del capital y en su beneficio. De algún modo, eso preludia la diferenciación entre capital (relación entre capital y salario) y capitalismo (relaciones heterogéneas entre capital y todas las demás formas de trabajo), que confronta anticipadamente a la teoría de la articulación de modos de producción, producida más tarde por el materialismo histórico. De otra parte, la idea según la cual las clases se forman, se desintegran o se con- solidan, parcial y temporalmente o de modo definido y permanente, según el curso de las luchas concretas de las gentes concretas, disputando el control de cada ámbito del poder. No son estructuras, ni categorías, anteriores a tales conflictos.

Esa línea de reflexión de Marx también está presente en El Capital, a pesar de todas sus conocidas ambigüedades. Por eso, la tercera propuesta establece una diferencia básica entre la perspectiva marxiana y la del materialismo histórico. Mientras que en éste las clases sociales son ocupantes de una suerte de nichos estructurales, donde son ubicadas y distribuidas las gentes por las relaciones de producción, en Marx se trata de un proceso histórico concreto de clasificación de las gentes. Esto es, un proceso de luchas en que unos logran someter a otros en la disputa por el control del trabajo y de los recursos de producción. En otros términos, las relaciones de producción no son externas, ni anteriores a las luchas de las gentes, sino el resultado de las luchas entre las gentes por el control del trabajo y de los recursos de producción, de las victorias de los unos y de las derrotas de otros, y como resultado de las cuales se ubican y/o son ubicadas o clasificadas. Esa es, sin duda, la propuesta teórica implicada en el famoso capítulo sobre la "acumulación 
originaria" ${ }^{18}$. De otro modo, la línea de análisis de El 18 Brumario de Luis Bonaparte no tendría sentido. En la línea marxiana, en consecuencia, las clases sociales no son estructuras, ni categorías, sino relaciones históricamente producidas y, en ese sentido, históricamente determinadas, aun cuando esa visión esté reducida a sólo uno de los ámbitos del poder: el trabajo. En cambio, en el materialismo histórico, tal como lo señala E. P. Thompson, se prolonga la visión "estática", es decir, ahistórica, que asigna a las clases sociales la calidad de estructuras establecidas por relaciones de producción, que vienen a la existencia por fuera de la subjetividad y de las acciones de las gentes, es decir, antes de toda historia.

El materialismo histórico ha reconocido, después de la segunda guerra mundial, que en su visión evolucionista y unidireccional de las clases sociales y de las sociedades de clase, hay pendientes problemas complicados. En primer lugar por la reiterada comprobación de que incluso en los "centros", algunas clases "precapitalistas", el campesinado en particular, no salían ni parecían dispuestas a salir de la escena histórica del "capitalismo", mientras que otras, las

18 Véase Karl Marx, El Capital (1966, Vol. I, cap. XXIV: 607 ss.). "clases medias", tendían a crecer conforme el capitalismo se desarrollaba. En segundo lugar, porque no era suficiente la visión dualista del pasaje entre "precapitalismo" y "capitalismo" respecto de las experiencias del "Tercer Mundo", en donde configuraciones de poder muy complejas y heterogéneas no corresponden a las secuencias y etapas esperadas en la teoría eurocéntrica del capitalismo. Sin embargo, el materialismo histórico no logró encontrar una salida teórica respaldada en la experiencia histórica, y arribó apenas a la propuesta de "articulación de modos de producción", sin abandonar la idea de la secuencia entre ellos. Es decir, tales "articulaciones" no dejan de ser coyunturas de la transición entre los modos "precapitalistas" y el "capitalismo"19. En otros términos, consisten

19 Esa línea caracterizó las investigaciones y los debates científico-sociales entre los marxistas estructuralistas franceses, sobre todo durante los años setenta (entre otros, Pierre Philippe Rey, Claude Meillassoux). En inglés, véase la compilación de Harold Wolpe: The Articulation of Modes of Production (1973). En América Latina, una parte de los investigadores optó por una perspectiva diferente, según la cual el capitalismo es una estructura de explotación / dominación donde se articulan todas las formas históricamente conocidas de explotación del trabajo, en torno de un eje común: las relaciones capital-salario. Es la línea seguida en mis 
en la coexistencia (transitoria, por supuesto) del pasado y el presente de su visión histórica. $\mathrm{Al}$ materialismo histórico le es ajena y hostil la idea de que no se trata de "modos de producción articulados", sino del capitalismo como estructura mundial de poder dentro del cual, y a su servicio, se articulan todas las formas históricamente conocidas de trabajo, de control y de explotación social del trabajo.

De otro lado, la idea de "clase" fue introducida en los estudios sobre la naturaleza antes que en los estudios sobre la sociedad. Fue el naturalista sueco, Linneo, el primero en usarla en su famosa clasificación botánica del siglo XVIII. Él descubrió que era posible clasificar las plantas según el número y la disposición de los estambres de las flores, porque éstas tienden a permanecer sin cambios en el curso de la evolución ${ }^{20}$. No pareciera haber sido básica-

propios trabajos, por ejemplo, en Lo cholo en el conflicto cultural peruano (1964); Imperialismo, clases sociales y Estado en el Perú (1973) y Naturaleza, situación y tendencias de la sociedad peruana (1969). Esa es la perspectiva denominada "histórico-estructural", que aparece ya desde mis "Notas sobre el concepto de marginalidad social” (1966).

20 Carlos Linneo (1707-1778) (Carolus Linnaeus, en latín, y en sueco, Carl Von Linné) fue el primero en elaborar un sistema de clasificación de las plantas desde mente distinta la manera de conocer que llevó, primero a los historiadores franceses del siglo XVIII, y después a los saintsimonianos de las primeras décadas del XIX, a clasificar en "clases" a la población europea. Para Linneo, las plantas estaban allí, en el "reino vegetal", dadas por naturaleza, y a partir de algunas de sus características, empíricamente diferenciables, era posible "clasificarlas". Los que estudiaban y debatían la sociedad de la Europa centronórdica, a fines del siglo XVIII y a comienzos del XIX, aplicaron la misma perspectiva a las gentes, y encontraron que era posible clasificarlas también a partir de sus características más constantes, en especial por su lugar en la estructura social de riqueza y pobreza, mando y obediencia. Fue un hallazgo saintsimoniano descubrir que la fuente principal de esas diferencias estaba en el control del trabajo y sus productos y de los recursos de la naturaleza empleados en el trabajo.

Los teóricos del materialismo histórico, desde fines del siglo XIX, no produjeron rupturas o mutaciones decisivas en esa perspectiva de conocimiento. Por supuesto, al transferir el sus-

1730. Véase James L. Larson, Reason and Experience: The Representation of Natural Order in the Work of Carl Von Linné (1971). 
tantivo "clase" del mundo de la naturaleza al de la sociedad, era indispensable asociarlo con un adjetivo que legitimara ese desplazamiento: la clase deja de ser botánica y se muta en social. Pero dicho desplazamiento fue básicamente semántico. El nuevo adjetivo no podía ser capaz, por sí solo, ni de cortar el cordón umbilical que ataba al recién nacido concepto al vientre naturalista, ni de proporcionarle para su desarrollo una atmósfera epistémica alternativa. En el pensamiento eurocéntrico, heredero de la Ilustración continental, la sociedad era un organismo, un orden dado y cerrado, y las clases sociales fueron pensadas como categorías ya dadas en la "sociedad", como ocurría con las plantas en la "naturaleza".

Debe tenerse en cuenta, en relación con esas cuestiones, que otros términos que tienen el mismo común origen naturalista -estructura, procesos, organismo-, en el eurocentrismo pasan al conocimiento social con las mismas ataduras cognitivas que el término clase. La obvia vinculación entre la idea eurocéntrica de las clases sociales con las ideas de "estructura" como un orden dado en la sociedad, y de "proceso" como algo que tiene lugar en una estructura, y de todas ellas con la idea orgánica y sistémica de "totalidad", ilumina con claridad la persistencia en ellas de todas las marcas cognitivas de su origen naturalista y, a través de ellas, de su duradera imprenta sobre la perspectiva eurocéntrica en el conocimiento histórico-social. No se podría entender, ni explicar de otro modo, la idea del materialismo histórico o de los sociólogos de la "sociedad industrial", según la cual, las gentes son "portadoras" de las determinaciones estructurales de clase y deben, en consecuencia, actuar según ellas. Sus deseos, preferencias, intenciones, voliciones, decisiones y acciones son configuradas según esas determinaciones, y deben responder a ellas. El problema creado por la inevitable distancia entre ese presupuesto y la subjetividad y la conducta externa de las gentes así clasificadas, encontró en el materialismo histórico una imposible solución: era un problema de la "conciencia", y ésta sólo podía ser llevada a los explotados por los intelectuales burgueses, como el polen es llevado a las plantas por las abejas (Kautsky-Lenin). O irse elaborando y desarrollando en una progresión orientada hacia una imposible "conciencia posible" (Lukács).

La impronta naturalista, positivista y marxista-positivista de la teoría eurocéntrica de las clases sociales, implica también dos cuestiones cruciales: 1) en su origen, la teoría de las clases sociales está pensada exclusivamente sobre la base de la experiencia europea, la 
cual, a su vez, está pensada según la perspectiva eurocéntrica; 2) las únicas diferencias que son percibidas entre los europeos como realmente significativas - una vez abolidas las jerarquías nobiliarias por la revolución francesa-se refieren a la riqueza / pobreza y al mando / obediencia. Diferencias que remiten, de un lado, al lugar y a los roles de las gentes respecto del control del trabajo y de los recursos que en la naturaleza sirven para trabajar (relaciones de producción), y de otro lado, a los lugares y roles de las gentes en el control de la autoridad, ergo, del Estado. Las otras diferencias que en la población europea de los siglos XVIII y XIX estaban vinculadas a diferencias de poder, principalmente sexo y edad, en esa perspectiva son "naturales", es decir, hacen parte de la clasificación en la "naturaleza". En otros términos, la teoría eurocéntrica sobre las clases sociales, y no solamente en el materialismo histórico marxista-positivista, o entre los weberianos, sino en el propio Marx, es reduccionista: se refiere única y exclusivamente a uno solo de los ámbitos del poder: el control del trabajo y de sus recursos y productos. $\mathrm{Y}$ eso es especialmente notable, sobre todo en Marx y sus herederos, pues no obstante que su propósito formal es estudiar, entender y cambiar o destruir el poder en la sociedad, todas las otras instancias de la existencia social en donde se forman relaciones de poder entre las gentes no son consideradas en absoluto, o son consideradas sólo como derivativas de las "relaciones de producción" y determinadas por ellas.

Todo aquello significa que la idea de clases sociales es elaborada en el pensamiento eurocéntrico, entre fines del siglo XVIII y fines del XIX, cuando ya la percepción de la totalidad desde Europa, por entonces el "centro" del mundo capitalista, ha sido ya definitivamente organizada como una dualidad histórica: Europa (para el caso, sobre todo Europa central e Inglaterra) y no-Europa. Y esa dualidad implicaba, además, que mucho de todo lo que era no-Europa, aunque existía en el mismo escenario temporal, en realidad correspondía al pasado de un tiempo lineal, cuyo punto de llegada era, obviamente, Europa. En la no-Europa existían, en ese mismo momento, siglo XIX, todas las formas no-salariales del trabajo. Pero desde Saint Simon hasta hoy, el eurocentrismo sólo ve en ellas el pasado "precapitalista" o "preindustrial". Es decir, esas clases sociales son "precapitalistas" o no existen. En la no-Europa habían sido impuestas identidades raciales no-europeas o "no-blancas". Pero ellas, como la edad o el género entre los europeos, corresponden a diferencias "naturales" de poder en- 
tre europeos y no-europeos. En Europa están en formación, o ya están formadas, las instituciones modernas de autoridad: los Estados-nación modernos y sus respectivas identidades. Pero en la no-Europa sólo son percibidas las tribus y las etnias como el pasado "pre-moderno", pues ellas serán reemplazadas en algún futuro por Estados-nación "como en Europa". Europa es civilizada. No-Europa es primitiva. El sujeto racional es europeo. La no-Europa es objeto de conocimiento. Como corresponde, la ciencia que estudiará a los europeos se llamará "Sociología", mientras la que estudiará a los noeuropeos se llamará "Etnografía".

A esta altura del debate no es, pues, suficiente mantenerse en los conocidos parámetros, porque eso no agota la cuestión, ni resuelve los problemas planteados en el conocimiento y en la acción. Limitarse a insistir en que es necesario historizar la cuestión de las clases sociales, es decir, referirla a la historia concreta de gentes concretas, en lugar de mantener una visión "estática" o ahistórica de las clases sociales, o poner a Weber en lugar de Marx, o explorar sus entrecruzamientos viables, como suele hacerse en la sociología escolar, ya es inconducente. En cualquiera de esas opciones, y en todas juntas, se trata sólo de clasificar a las gentes por algunas de sus dadas características diferenciales, y no hay realmente nada fundamental que ganar si son tales o cuales las características que se escogen, o deben ser escogidas, para que la operación clasificatoria resulte menos "ideológica" y más "objetiva".

Con la clasificación de los elementos de la naturaleza lo que importaba era, como correspondía a la racionalidad cartesiana, descubrir las "propiedades" que definen y al mismo tiempo emparentan a determinados "objetos" entre sí, o los distinguen individualmente y muestran su género próximo y su diferencia específica. Pero con la cuestión de las clases sociales, lo que realmente está en juego, y lo estuvo desde el comienzo en el propósito de quienes introdujeron la idea, es algo radicalmente distinto: la cuestión del poder en la sociedad. Y el problema es que ninguna de aquellas opciones, ni juntas, ni por separado, son aptas para permitir aprehender e indagar la constitución histórica del poder, y mucho menos la del poder capitalista, mundial y colonial / moderno.

Por todo eso, es pertinente salir de la teoría eurocéntrica de las clases sociales y avanzar hacia una teoría histórica de la clasificación social. El concepto de clasificación social, en esta propuesta, se refiere a los procesos de largo plazo, en los cuales las gentes disputan por el control de los ámbitos básicos de existencia 
social, y de cuyos resultados se configura un patrón de distribución del poder, centrado en relaciones de explotación / dominación / conflicto entre la población de una sociedad y en una historia determinadas. Fue ya señalado que el poder, en este enfoque, es una malla de relaciones de explotación / dominación / conflicto que se configuran entre las gentes, en la disputa por el control del trabajo, de la "naturaleza", del sexo, de la subjetividad y de la autoridad. Por lo tanto, el poder no se reduce a las "relaciones de producción", ni al "orden y autoridad", separados o juntos. Y la clasificación social se refiere a los lugares y a los roles de las gentes en el control del trabajo, sus recursos (incluidos los de la "naturaleza") y sus productos; del sexo y sus productos; de la subjetividad y sus productos (ante todo el imaginario y el conocimiento); y de la autoridad, sus recursos y sus productos.

En ese sentido específico, toda posible teoría de la clasificación social de las gentes requiere, necesariamente, indagar por la historia, las condiciones y las determinaciones de una dada distribución de relaciones de poder en una sociedad específica. Porque es esa distribución del poder entre las gentes de una sociedad la que las clasifica socialmente, determina sus recíprocas relaciones y genera sus diferencias sociales, ya que sus características, empíricamente observables y diferenciables, son resultado de esas relaciones de poder, sus señales y sus huellas. Se puede partir de éstas para un primer momento y un primer nivel de aprehensión de las relaciones de poder, pero no tiene sentido hacer residir en ellas la naturaleza de su lugar en la sociedad. Es decir, su clase social.

\section{HETEROGENEIDAD DE LA CLASIFICACIÓN SOCIAL}

Desde la inserción de América en el capitalismo mundial moderno / colonial, las gentes se clasifican y son clasificadas según tres líneas diferentes, pero articuladas en una estructura global común por la colonialidad del poder: trabajo, género y raza. La edad no llega a ser insertada de modo equivalente en las relaciones sociales de poder, pero sí en determinados ámbitos del poder. Y en torno de dos ejes centrales: el control de la producción de recursos de sobrevivencia social y el control de la reproducción biológica de la especie. El primero implica el control de la fuerza de trabajo, de los recursos y productos del trabajo, lo que incluye los recursos "naturales", y se institucionaliza como 
"propiedad". El segundo implica el control del sexo y sus productos (placer y descendencia), en función de la propiedad. La "raza" fue incorporada en el capitalismo eurocentrado en función de ambos ejes. Y el control de la autoridad se organiza para garantizar las relaciones de poder así configuradas. En esa perspectiva, las "clases sociales" resultantes son heterogéneas, discontinuas, conflictivas, y están articuladas también de modo heterogéneo, discontinuo y conflictivo. La colonialidad del poder es el eje que las articula en una estructura común, como podrá ser mostrado más adelante. En tanto que todos los elementos que concurren a la constitución de un patrón de poder son de origen, forma y carácter discontinuos, heterogéneos, contradictorios y conflictivos en el espacio y en el tiempo, es decir, cambian o pueden cambiar en cada una de esas instancias, en función de sus cambiantes relaciones con cada uno de los otros, las relaciones de poder no son, no pueden ser, una suerte de nichos estructurales preexistentes, en donde las gentes son distribuidas, y de los cuales asumen tales o cuales características y se comportan o deben comportarse acordemente.

El modo como las gentes llegan a ocupar, total o parcialmente, transitoria o establemente, un lugar y un papel respecto del control de las instancias centrales del poder, es conflictivo. Es decir, consiste en una disputa, violenta o no, en derrotas y en victorias, en resistencias, y en avances y retrocesos. Ocurre en términos individuales y/o colectivos, con lealtades y traiciones, persistencias y deserciones. Y, puesto que toda estructura de relaciones es una articulación de discontinuos, heterogéneos y conflictivos ámbitos y dimensiones, los lugares y los papeles no necesariamente tienen o pueden tener las mismas ubicaciones y relaciones en cada ámbito de la existencia social, o en cada momento del respectivo espacio / tiempo. Esto es, las gentes pueden tener, por ejemplo, un lugar y un papel respecto del control del trabajo, y otro bien diferente y hasta opuesto respecto del control del sexo o de la subjetividad, o en las instituciones de autoridad. Y no siempre los mismos en el curso del tiempo.

Desde ese punto de vista, la idea eurocéntrica de que las gentes que, en un dado momento de un patrón de poder, ocupan ciertos lugares y ejercen ciertos roles, constituyan por esos solos factores una comunidad o un sujeto histórico, apunta en una dirección históricamente inconducente. Semejante idea sólo sería admisible si fuera posible admitir también que tales gentes ocupan lugares y cumplen papeles simétricamente consistentes entre sí, en cada 
una de las instancias centrales del poder. La distribución de las gentes en las relaciones de poder tiene, en consecuencia, el carácter de procesos de clasificación, des-clasificación y re-clasificación social de una población, es decir, el carácter de aquella articulada dentro de un patrón social de poder de larga duración. No se trata aquí solamente del hecho de que las gentes cambian y pueden cambiar su lugar y sus papeles en un patrón de poder, sino de que tal patrón, como tal, está siempre en cuestión, puesto que las gentes están disputando todo el tiempo, y los recursos, razones y necesidades de esos conflictos nunca son los mismos en cada momento de una larga historia. En otros términos, el poder está siempre en estado de conflicto y en procesos de distribución y de redistribución. Sus periodos históricos pueden ser distinguidos, precisamente, en relación con tales procesos ${ }^{21}$.

21 Dejo para otro trabajo el debate más detenido sobre la cuestión del "sujeto histórico", que ha sido puesto en la mesa por las corrientes posmodernistas. Por el momento creo necesario indicar, apenas, primero mi escepticismo respecto de la noción de "sujeto histórico", porque remite, quizás inevitablemente, a la herencia hegeliana, no del todo "invertida" en el materialismo histórico. Esto es, a una cierta mirada teleológica de la historia y a un "sujeto" orgánico o sistémico, por-
De una propuesta alternativa al eurocentrismo no se desprende, en consecuencia, que una población afectada en un momento y una forma del proceso de clasificación social, no llegue a tener los rasgos de un grupo real, de una comunidad y de un sujeto social. Pero tales rasgos sólo se constituyen como parte y resultado de una historia de conflictos, de un patrón de memoria asociado a esa historia y que es percibido como una identidad, y que produce una voluntad y una decisión de trenzar las heterogéneas y discontinuas experiencias particulares en una articulación subjetiva colectiva, que se constituye en un elemento de las relaciones reales materiales. Las luchas colectivas

tador del movimiento respectivo, orientado en una dirección ya determinada. Tal "sujeto" sólo puede existir, en todo caso, no como histórico, sino, bien al contrario, como metafísico. De otro lado, sin embargo, la simple negación de toda posibilidad de subjetivación de un conjunto de gentes, de su constitución como sujeto colectivo bajo ciertas condiciones y durante un cierto tiempo, va directamente contra la experiencia histórica, si no admite que lo que puede llamarse "sujeto", no sólo colectivo, sino inclusive individual, está siempre constituido por elementos heterogéneos y discontinuos, y que llega a ser una unidad sólo cuando esos elementos se articulan en torno de un eje específico, bajo condiciones concretas, respecto de necesidades concretas y de modo transitorio. 
de sectores de trabajadores que llegan a organizarse en sindicatos, en partidos políticos, las de identidades llamadas "nacionales y/o étnicas", las de comunidades, inclusive, mucho más amplias, que se agrupan como identidades religiosas, y que son perdurables por largos plazos, son ejemplos históricos de tales procesos de subjetivación de amplias y heterogéneas poblaciones, que son incluso discontinuos en el tiempo y en el espacio.

Sin embargo, no todos los procesos de subjetivación social o de constitución de sujetos colectivos pueden ser reconocidos como procesos de clasificación social. En algunos casos se trata de un problema de formación de identidades, de un proceso identitario que no pone en cuestión, para nada, esas instancias de poder social. Desde nuestra perspectiva, sólo los procesos de subjetivación, cuyo sentido es el conflicto en torno de la explotación / dominación, constituyen procesos de clasificación social. En el capitalismo mundial la cuestión del trabajo, de la raza y del género, son las tres instancias centrales respecto de las cuales se ordenan esas relaciones conflictivas de explotación / dominación. Ergo, los procesos de clasificación social consistirán, de todos modos, en procesos donde esas tres instancias se asocian o se disocian respecto del complejo ex- plotación / dominación / conflicto. De las tres instancias es el trabajo, esto es, la explotación / dominación, la que se ubica como el ámbito central y permanente. La dominación hace posible la explotación y no se la encuentra, sino muy raramente, actuando por separado. Las otras instancias son, ante todo, instancias de dominación, ya que la explotación sexual, específicamente, es discontinua. Esto es, mientras que la relación de explotación / dominación entre capital-trabajo es continua, el mismo tipo de relación varón-mujer no ocurre en todos los casos, ni en todas las circunstancias; no es, pues, continua. Así mismo, en la relación entre "razas" se trata, ante todo, de dominación. En fin, la articulación entre instancias de explotación y de dominación es heterogénea y discontinua. Y, por lo mismo, la clasificación social como un proceso en el cual las tres instancias están asociadas / disociadas, tiene también, necesariamente, esas características.

Una idea, que originalmente fue propuesta con claro carácter histórico por Marx, fue posteriormente mistificada en el materialismo histórico: el interés de clase. En la medida en que la idea de clase se hizo reduccionista y se ahistorizó, el interés de clase en el capitalismo fue reducido a la relación entre capital y salario. Los intereses de los demás trabajado- 
res fueron siempre vistos como secundarios y susceptibles de ser subordinados a los de los asalariados obreros, y en particular a los de la llamada clase obrera industrial.

¿Qué ocurre, sin embargo, si se asume, como es imperativo hoy, que el capitalismo articula y explota a los trabajadores bajo todas las formas de trabajo, y que los mecanismos de dominación usados para ese efecto -"raza" y "género"- son usados diferenciadamente en ese heterogéneo universo de trabajadores? En primer término, el concepto de interés de clase requiere ser pensado también en términos de su heterogeneidad histórico-estructural.

En seguida, es necesario establecer, en cada momento y en cada contexto específico, el eje común de relación de explotación / dominación / conflicto entre todos los trabajadores, sometidos a todas las formas de trabajo y a todas las formas de dominación, con el capital y sus funcionarios. Por esas razones, acerca de la clasificación social o procesos de subjetivación social frente a la explotación / dominación, la cuestión central es la determinación de las condiciones históricas específicas respecto de las cuales es posible percibir los modos, los niveles y los límites de la asociación de las gentes implicadas en esas tres instancias (trabajo, género y raza), en un periodo y en un contexto específicos.
De todos modos, ningún proceso de clasificación social, de subjetivación de las gentes frente al capitalismo, podrá ser suficientemente seguro para reproducirse y sostenerse por el periodo necesario para llevar a las víctimas de la explotación / dominación capitalista a su liberación, si, desde la perspectiva inmediata de las gentes concretas implicadas, esas tres instancias son percibidas y manejadas de modo separado o, peor, en conflicto. No por acaso, mantener, acentuar y exasperar entre los explotados / dominados la percepción de esas diferenciadas situaciones, en relación con el trabajo, la raza y el género, ha sido y es un medio extremamente eficaz de los capitalistas para mantener el control del poder. La colonialidad del poder ha tenido en esta historia el papel central.

\section{COLONIALIDAd DEL PODER Y CLASIFICACIÓN SOCIAL}

En la historia conocida antes del capitalismo mundial se puede verificar que, en las relaciones de poder, ciertos atributos de la especie han jugado un papel principal en la clasificación social de las gentes: sexo, edad y fuerza de trabajo son sin duda los más antiguos. Desde 
la conquista de América se añadió el fenotipo. El sexo y la edad son atributos biológicos diferenciales, aunque su lugar en las relaciones de explotación / dominación / conflicto está asociado a la elaboración de dichos atributos como categorías sociales. En cambio, la fuerza de trabajo y el fenotipo no son atributos biológicos diferenciales. El color de la piel, la forma y el color del cabello, de los ojos, la forma y el tamaño de la nariz, etc., no tienen ninguna consecuencia en la estructura biológica de la persona $\mathrm{y}$, ciertamente, menos aún en sus capacidades históricas. $\mathrm{Y}$, del mismo modo, ser trabajador "manual" o "intelectual" no tiene relación con la estructura biológica. En otros términos, el papel que cada uno de esos elementos juega en la clasificación social, esto es, en la distribución del poder, no tiene nada que ver con la biología, ni con la "naturaleza". Tal papel es el resultado de las disputas por el control de los ámbitos sociales.

Por lo mismo, la naturalización de las categorías sociales que dan cuenta del lugar de esos elementos en el poder es un desnudo producto histórico social. El hecho de que las categorías, que identifican lugares y papeles en las relaciones de poder, tengan la pretensión de ser simplemente nombres de fenómenos "naturales", tengan o no alguna referencia real en la naturaleza, es una indicación muy eficaz de que el poder, todo poder, requiere de ese mecanismo subjetivo para su reproducción. $\mathrm{Y}$ es interesante preguntarse por qué. Mientras la producción social de la categoría "género", a partir del sexo, es sin duda la más antigua en la historia social, la producción de la categoría "raza", a partir del fenotipo, es relativamente reciente, y su plena incorporación a la clasificación de las gentes en las relaciones de poder tiene apenas quinientos años: comienza con América y la mundialización del patrón de poder capitalista ${ }^{22}$.

22 Llevaría a otra parte discutir aquí extensa y específicamente la cuestión racial. Remito a mi estudio "Raza, etnia, nación: cuestiones abiertas" (1992). La literatura de este debate no cesa de crecer. Quizás la más útil entre las publicaciones recientes sea la de Jonathan Marks, Human Biodiversity. Genes, Race and History (1995). Entre los menos recientes, véase la compilación de Raymond Mack, Race, Class, and Power (1963). Ciertas almas piadosas quisieran la igualdad entre las razas, pero juran que éstas son realmente existentes. Así, virtualmente en todas las universidades de Estados Unidos, hay cátedras sobre "Race and Ethnicity", y el servicio de Migraciones tiene una prolija clasificación racista / etnicista, basada en los rasgos fenotípicos (color, sobre todo), aunque el gobierno federal haya sido obligado a admitir la "igualdad racial". Casi todos los indígenas de otros países que estudiaron en esas univer- 
Las diferencias fenotípicas entre vencedores y vencidos han sido usadas como justificación de la producción de la categoría "raza", aunque se trata, ante todo, de una elaboración de las relaciones de dominación como tales. La importancia y la significación de la producción de esta categoría para el patrón mundial de poder capitalista eurocéntrico y colonial / moderno, difícilmente podría ser exagerada: la atribución de las nuevas identidades sociales resultantes y su distribución en las relaciones de poder mundial capitalista, se estableció y se reprodujo como la forma básica de la clasificación social universal del capitalismo mundial, y como el fundamento de las nuevas identidades geoculturales y de sus relaciones de poder en el mundo. Y, así mismo, llegó a ser el trasfondo de la producción de las nuevas relaciones intersubjetivas de dominación, y de una perspectiva de conocimiento mundialmente impuesta como la única racional. La racialización de las relaciones de poder entre las nuevas identidades sociales y geoculturales fue el sustento y la referencia legitimadora fundamental del carácter

sidades y pasaron por ese servicio de migraciones, regresan a sus países convertidos a la religión del "colour consciousness", y proclaman la realidad de la "raza". eurocentrado del patrón de poder, material e intersubjetivo. Es decir, de su colonialidad. Se convirtió, así, en el más específico de los elementos del patrón mundial de poder capitalista eurocentrado y colonial / moderno, y penetró cada una de las áreas de la existencia social del patrón de poder mundial, eurocentrado, colonial / moderno. Hace falta estudiar y establecer, de modo sistemático (no sistémico), las implicaciones de la colonialidad del poder en el mundo capitalista. En los límites de este texto, me restringiré a proponer un esquema de las principales cuestiones.

\section{A. Colonialidad de la Clasificación SOCIAL UNIVERSAL DEL MUNDO CAPITALISTA}

Lo que comenzó con América fue mundialmente impuesto. La población de todo el mundo fue clasificada, ante todo, en identidades "raciales", y dividida entre los dominantes / superiores "europeos" y los dominados / inferiores "no-europeos". Las diferencias fenotípicas fueron usadas, definidas, como expresión externa de las diferencias "raciales": en un primer periodo, principalmente el "color" de la piel y del cabello y la forma y el color de los ojos; más tarde, en los siglos XIX y XX, también 
otros rasgos como la forma de la cara, el tamaño del cráneo, la forma y el tamaño de la nariz. El color de la piel fue definido como la marca "racial" diferencial más significativa, por más visible, entre los dominantes / superiores o "europeos", de un lado, y el conjunto de los dominados / inferiores "no-europeos", del otro lado. De ese modo, se adjudicó a los dominadores / superiores europeos el atributo de "raza blanca", y a todos los dominados / inferiores "no-europeos", el atributo de "razas de color"23. La escalera de gradación entre el "blanco" de la "raza blanca" y cada uno de los otros "colores" de la piel fue asumida como una gradación entre lo superior y lo inferior en la clasificación social "racial".

23 El proceso de la producción social del color, como el signo principal de una clasificación social universal del mundo colonial / moderno y eurocentrado del capitalismo, es todavía una cuestión cuya investigación histórica sistemática está por hacerse. Aquí es indispensable señalar que, antes de América, el "color" no se registra como clasificador de las gentes en las relaciones de poder. El eurocentramiento del nuevo patrón de poder no fue, sin duda, inevitable. Pero fue su establecimiento lo que dio origen, explicación y sentido a la imposición de la categoría "raza", y del "color" como su marca externa, desde el siglo XVI hasta hoy.

\section{B. Colonialidad de la ARTiculación POLÍTICA Y NEOCULTURAL}

Los territorios y las organizaciones políticas de base territorial, colonizadas parcial o totalmente o no colonizadas, fueron clasificados en el patrón eurocentrado del capitalismo colonial/moderno, precisamente, según el lugar que las "razas" y sus respectivos "colores" tenían en cada caso. Así se articuló el poder entre "Europa", “América”, "África”, "Asia” y, mucho más tarde, "Oceanía”. Eso facilitó la naturalización del control eurocentrado de los territorios, de los recursos de producción en la "naturaleza". Y cada una de esas categorías, impuestas desde el eurocentro del poder, ha terminado siendo finalmente admitida hasta hoy, para la mayoría, como expresión de la naturaleza y de la geografía, no de la historia del poder en el planeta. Los grupos dominantes de las razas no-blancas fueron sometidos a ser tributarios, es decir, intermediarios en la cadena de transferencia de valor y de riquezas de la periferia colonial al eurocentro, o asociados dependientes. Los Estados-nación del centro se constituyeron teniendo como contrapartida los Estados coloniales primero, y los Estados-nación dependientes después. 
Como parte de esa relación, los procesos de ciudadanización, de representación desigual pero real de los diversos sectores sociales, la retribución en servicios públicos de la producción y de la tributación de los trabajadores (llamado Welfare State), no ha dejado de ser, en definitiva, privilegio del centro, porque su costo se paga en muy amplia medida por la explotación del trabajo de la periferia colonial en condiciones no democráticas y no nacionales, esto es, como sobre-explotación. Debido a esas determinaciones, todos los países cuyas poblaciones son, en su mayoría, víctimas de relaciones racistas o etnicistas de poder, no han logrado salir de la periferia colonial, en la disputa por el "desarrollo"24. Y los países que han llegado a incorporarse al "centro", o están en camino de hacerlo, son aquellos cuyas sociedades, o no tienen relaciones de colonialidad, porque, precisamente, no fueron colonias europeas, o lo fueron pero de modo muy corto y muy parcial (Japón, Taiwán, China), o países en donde las poblaciones colonizadas fueron en un comienzo minorías pequeñas, como los "negros" al formarse Estados Unidos de Norte

24 Sobre la relación entre colonialidad y desarrollo, véase mi texto "América Latina en la economía mundial" (1993).
América, o donde las poblaciones aborígenes fueron reducidas a minorías aisladas, si no exterminadas, como sucedió en Estados Unidos, Canadá, Australia y Nueva Zelandia. De allí se desprende, de nuevo, que la colonialidad del poder implica, en las relaciones internacionales de poder y en las relaciones internas dentro de los países, lo que en América Latina ha sido denominado como dependencia histórico-estructural.

\section{Colonialidad de la distribución MUNDIAL DEL TRABAJO}

No menos decisiva para el capitalismo eurocentrado moderno / colonial fue la distribución mundial de trabajo en torno de la colonialidad del poder. El capitalismo ha organizado la explotación del trabajo en un complejo engranaje mundial, en torno del predominio de la relación capital-salario. Para muchos teóricos, en eso consiste todo el capitalismo. Todo lo demás es "precapitalista" y, de esa manera, externo al capital. Sin embargo, desde América sabemos que la acumulación capitalista no ha prescindido, en momento alguno, de la colonialidad del poder hasta hoy día.

El esquema de un mundo capitalista, dualmente ordenado en "centro" y "periferia", no 
es arbitrario precisamente por esa razón, aunque probablemente habría sido mejor pensar en "centro colonial" y "periferia colonial" (en el sentido de la colonialidad, y no sólo, y no tanto, del colonialismo), para evitar la secreción "naturalista", físico-geográfica de la imagen. En el centro (eurocentro), la forma dominante, no sólo estructuralmente, sino también, a largo plazo, demográficamente, de la relación capital-trabajo, fue salarial. Es decir que la relación salarial fue, principalmente, "blanca". En la "periferia colonial", en cambio, la relación salarial fue, con el tiempo, estructuralmente dominante, pero siempre minoritaria en la demografía como en todo lo demás, mientras que las más extendidas y sectorialmente dominantes fueron todas las otras formas de explotación del trabajo: esclavitud, servidumbre, producción mercantil simple, reciprocidad. Pero todas ellas estuvieron, desde el comienzo, articuladas bajo el dominio del capital y en su beneficio.

Globalmente, la relación salarial ha sido siempre, hoy inclusive, la menos extendida geográfica y demográficamente. El universo mundial del trabajo y de los trabajadores del capital fue, en cambio, diverso y heterogéneo. En consecuencia, las "clases sociales" entre la población del mundo, no sólo no se redujeron al lugar de las gentes en el control del trabajo y de sus productos, sino que, inclusive en ese restricto ámbito, quedaron ordenadas sobre la base principal de la colonialidad del poder. En el eurocentro, pensado de modo aislado y separado de la periferia colonial, la clasificación social apareció, inevitablemente, sólo en relación con el trabajo, ya que los "europeos" no se percibían aún como racialmente diferenciados, como, en cambio, sí lo hacen hoy, cuando las poblaciones víctimas de la colonialidad del poder han logrado instalarse en las sedes originales de los colonizadores. Las "clases sociales" fueron, por eso, conceptualmente separadas y diferenciadas de las "razas", y sus recíprocas relaciones fueron pensadas como externas. Globalmente, sin embargo, como fue siempre la condición misma de existencia del capitalismo, las "clases sociales" fueron diferenciadamente distribuidas entre la población del planeta, sobre la base de la colonialidad del poder: en el eurocentro los dominantes son capitalistas, mientras que los dominados son los asalariados, las clases medias y los campesinos independientes; en la periferia colonial, en cambio, los dominantes son capitalistas tributarios y/o asociados dependientes, mientras que los dominados son esclavos, siervos, peque- 
ños productores mercantiles independientes, asalariados, clases medias y campesinos. Esa clasificación social diferenciada, entre el centro y la periferia colonial, ha sido el mecanismo central del engranaje de acumulación global en beneficio del centro. De hecho, es lo que ha permitido producir, mantener y costear la lealtad de los explotados / dominados "blancos" frente a las "razas", ante todo en la "periferia colonial", pero también dentro del "centro", como no ha terminado de ocurrir, sobre todo en Estados Unidos.

\section{Colonialidad de las Relaciones DE GÉNERO}

En todo el mundo colonial, las normas y los patrones formal-ideales de comportamiento sexual de los géneros y, en consecuencia, los patrones de organización familiar de los "europeos" fueron directamente fundados en la clasificación racial: la libertad sexual de los varones y la fidelidad de las mujeres fue, en todo el mundo eurocentrado, la contrapartida del "libre" -esto es, no pagado como en la prostitución- acceso sexual de los varones blancos a las mujeres negras e indias. En Europa, en cambio, fue la prostitución de las mujeres la contrapartida del patrón de familia burguesa.
La unidad e integración familiar, impuestas como ejes del patrón de familia burguesa del mundo eurocentrado, fue la contrapartida de la continuada desintegración de las unidades de parentesco en las razas no-blancas, apropiables y distribuibles, no sólo como mercancías, sino directamente como animales. En particular entre los esclavos negros, ya que sobre ellos esa forma de dominación fue más explícita, inmediata y prolongada. La característica hipocresía subyacente a las normas y valores formal-ideales de la familia burguesa, no es, desde entonces, ajena a la colonialidad del poder.

\section{E. Colonialidad de las Relaciones CULTURALES O INTERSUBJETIVAS}

Ya quedaron anotadas muchas de las implicaciones mayores de la hegemonía del eurocentrismo en las relaciones culturales, intersubjetivas en general, en el mundo del capitalismo colonial / moderno. Aquí apenas vale apuntar lo siguiente. En todas las sociedades donde la colonización implicó la destrucción de la estructura social, la población colonizada fue despojada de sus saberes intelectuales y de sus medios de expresión exteriorizantes u objetivantes. Fueron reducidos a la condición de 
gentes rurales e iletradas. En las sociedades donde la colonización no logró la total destrucción social, las herencias intelectual y estético-visual no pudieron ser destruidas, pero fue impuesta la hegemonía de la perspectiva eurocéntrica en las relaciones intersubjetivas con los dominados. A largo plazo, en todo el mundo eurocentrado se fue imponiendo la hegemonía del modo eurocéntrico de percepción y de producción de conocimientos, y en una parte muy amplia de la población mundial el propio imaginario fue colonizado. Last but not least, la hegemonía eurocéntrica en la cultura del mundo capitalista ha implicado una manera mistificada de percepción de la realidad, lo mismo en el centro que en la periferia colonial. Pero sus efectos en la última, en el conocimiento y en la acción, han sido casi siempre históricamente conducentes a callejones sin salida. La cuestión nacional, la cuestión de la revolución, la cuestión de la democracia son sus emblemáticos ejemplos.

\section{F. DoMinación / EXPLOTACión, COLONIALIDAD Y CORPOREIDAD}

Hay una relación clara entre la explotación y la dominación: no toda dominación implica explotación, pero ésta no es posible sin aquella. La dominación es, por lo tanto, sine qua non del poder, de todo poder. Esta es una vieja constante histórica. La producción de un imaginario mitológico es uno de sus más característicos mecanismos. La naturalización de las instituciones y categorías que ordenan las relaciones de poder, impuestas por los vencedores / dominadores, ha sido hasta ahora su procedimiento específico. En el capitalismo eurocentrado, es sobre la base de la naturalización de la colonialidad de poder que la "cultura universal" fue impregnada de mitología y de mistificación en la elaboración de fenómenos de la realidad. La lealtad racial de los blancos frente a las otras razas ha servido como la piedra angular de la lealtad, incluso nacional, de los explotados y dominados "blancos" respecto de sus explotadores en todo el mundo y, en primer término, en el "eurocentro" 25.

25 Se trata de un fenómeno muy conocido, como lo testimonia la continuada segregación de los "negros" en las centrales sindicales dirigidas por "blancos" en los Estados Unidos. Pero no afecta sólo a los trabajadores mismos, sino, peor, a sus ideólogos y líderes políticos, que se reclaman socialistas. Los más ilustrativos ejemplos son la división entre todos los socialistas, primero, y de los marxistas después, frente al racismo y al colonialismo en África y en Asia, en los siglos XIX y XX. Ver 
La "naturalización" mitológica de las categorías básicas de la explotación / dominación es un instrumento de poder excepcionalmente poderoso. El ejemplo más conocido es la producción del "género" como si fuera idéntico a sexo. Muchas gentes piensan que ocurre lo mismo con "raza" respecto, sobre todo, de "color". Pero esta es una radical confusión. Después de todo, el sexo es realmente un atributo biológico (implica procesos biológicos) y algo tiene que ver con el "genero". Pero el "color" es, literalmente, un invento eurocéntrico en tanto que referencia "natural" o biológica de "raza", ya que nada tiene que hacer con la biología. Y, encima, el "color" en la sociedad colonial / moderna no siempre ha sido el más importante de los elementos de racialización efectiva o de los proyectos de racialización, como en el caso de los "arios" respecto de los demás "blancos", incluidos los "blancos" "judíos", y, más recientemente, en los procesos de racialización de las relaciones árabeisraelíes. Estas son, si falta hiciera, eficientes demostraciones históricas del carácter estrictamente mítico-social de la relación entre "color" y "raza".

el documentado estudio de Horace Davis, Nationalism and Socialism (1967).
"Raza" es una categoría cuyo origen intersubjetivo es, en ese sentido, demostrable. ¿Por qué, entonces, ha llegado a ser tan presente en la sociedad "moderna", tan profundamente introyectada en el imaginario mundial, como si fuera realmente "natural" y material? Sugiero un camino de indagación: porque implica algo muy material: el cuerpo humano. La corporalidad es el nivel decisivo de las relaciones de poder. Porque el "cuerpo" menta a la "persona", si se libera el concepto de "cuerpo" de las implicaciones mistificatorias del antiguo dualismo judeocristiano (alma-cuerpo, psiquis-cuerpo, etcétera). Y eso es lo que hace posible la "naturalización" de tales relaciones sociales. En la explotación, es el cuerpo el que es usado y consumido en el trabajo y, en la mayor parte del mundo, en la pobreza, en el hambre, en la malnutrición, en la enfermedad. Es el cuerpo el implicado en el castigo, en la represión, en las torturas y en las masacres durante las luchas contra los explotadores.

Pinochet es un nombre de lo que le ocurre a los explotados en su "cuerpo" cuando son derrotados en esas luchas. En las relaciones de género, se trata del cuerpo. En la "raza", la referencia es al cuerpo, pues el "color" presume el cuerpo. Hoy, la lucha contra la ex- 
plotación / dominación implica, sin duda, en primer término, la lucha por la destrucción de la colonialidad del poder, no sólo para terminar con el racismo, sino por su condición de eje articulador del patrón universal del capitalismo eurocentrado. Esa lucha es parte de la destrucción del poder capitalista, por ser hoy la trama viva de todas las formas históricas de explotación, dominación, discriminación, materiales e intersubjetivas. El lugar central de la "corporeidad", en este plano, lleva a la necesidad de pensar, de repensar, vías específicas para su liberación, esto es, para la liberación de las gentes, individualmente y en sociedad, del poder, de todo poder. Y la experiencia histórica hasta aquí apunta a que no hay camino distinto que la socialización radical del poder para llegar a ese resultado. Eso significa, la devolución a las gentes mismas, de modo directo e inmediato, del control de las instancias básicas de su existencia social: trabajo, sexo, subjetividad, autoridad.

\section{Bibliografía}

Anrup, Roland 1985 "Totalidad social: ¿unidad conceptual o unicidad real?" en Revista de
Extensión Cultural Universidad Nacional de Colombia, $\mathrm{N}^{\circ}$ 20: 5-23.

Davis, Horace 1967 Nationalism and Socialism (Nueva York: Monthly Review Press).

González Casanova, Pablo 1965 "Internal Colonialism and National Development" en Studies in Comparative International Development, $\mathrm{N}^{\circ} 1-4$.

Haya de la Torre, Raúl 1932 El Antiimperialismo y el APRA (Santiago: Ercilla).

Hindess y Hirst 1975 Pre-Capitalist Modes of Production (Londres: Routledge).

Laclau, Ernesto y Mouffe, Chantal 1985 Hegemony and Socialist Strategy (Londres: Verso).

Larson, James L. 1971 Reason and Experience: The Representation of Natural Order in the Work of Carl Von Linné (Nueva York: s/d).

Mack, Raymond 1963 Race, Class, and Power (Nueva York: American Book).

Mariátegui, José Carlos 19287 Ensayos de interpretación de la realidad peruana (Lima: s/d).

Marks, Jonathan 1995 Human Biodiversity. Genes, Race and History (Nueva York: Aldine de Gruyter).

Marx, Karl 1966 El Capital (México: Fondo de Cultura Económica) Vols. I, II y III.

Marx, Karl y Engels, Frederic 1947 "Carta a Weydemeyer (Londres, 5 de marzo de 1852)" en Correspondencia (Buenos Aires: Problemas) pp. 71-74. 
Meiksins Wood, Ellen 1986 A Retreat from Class: A New 'True' Socialism (Londres: Verso).

Olin Wright, Erik 1978 Class, Crisis and the State (s/d: NLB).

Parkin, Frank 1979 Marxism and Class Theory. A Bourgeois Critique (Nueva York: Columbia University Press).

Poulantzas, Nicos 1968 Pouvoir et Classes Sociales (París: s/d).

Prebisch, Raúl 1981 Capitalismo periférico, crisis y transformación (México: Fondo de Cultura Económica).

Prebisch, Raúl 1976 “Crítica al capitalismo periférico" en Revista de la CEPAL (Santiago de Chile: CEPAL) $1^{\circ}$ semestre.

Prebisch, Raúl 1963 Hacia una dinámica del desarrollo latinoamericano (México: Fondo de Cultura Económica).

Quijano, Aníbal 1994 "Colonialité du Pouvoir et Democratie en Amerique Latine” en Future Anterieur: Amerique Latine, democratie et exclusion (Paris: L' Harmattan).

Quijano, Aníbal 1993 “América Latina en la economía mundial” en Problemas del desarrollo (México: Instituto de Investigaciones Económicas-UNAM) Vol. XXIV, N 95, octubre-diciembre.

Quijano, Aníbal 1992 "Raza, etnia, nación: cuestiones abiertas" en José Carlos Mariátegui y Europa (Lima: Amauta).

Quijano, Aníbal 1991a “Colonialidad y modernidad / racionalidad" en Perú Indígena (Lima) Vol. 13, N² 29: 11-29.

Quijano, Aníbal 1991b "La modernidad, el capitalismo y América Latina nacen el mismo día” en $I L L A, \mathrm{~N}^{\circ} 10$, enero.

Quijano, Aníbal 1988 Modernidad, identidad y utopía en América Latina (Lima: Sociedad y Política).

Quijano, Aníbal 1973 Imperialismo, clases sociales y Estado en el Perú (s/d).

Quijano, Aníbal 1969 Naturaleza, situación y tendencias de la sociedad peruana (Santiago de Chile: Centro de Estudios Socio-Económicos).

Quijano, Aníbal 1966 Notas sobre el concepto de marginalidad social (Santiago de Chile: CEPAL).

Quijano, Aníbal 1964 Lo cholo en el conflicto cultural peruano (Lima: s/d).

Quijano, Aníbal y Wallerstein, Immanuel 1992 "Americanity as a Concept or the Americas in the Modern World System" en International Journal of Social Sciences, $\mathrm{N}^{\circ} 134$, noviembre.

Shanin, Theodor 1984 The Late Marx: The Russian Road (Nueva York: MR Press).

Stavenhagen, Rodolfo 1965 "Clases, Colonialism and Acculturation" en Studies in Comparative International Development, $\mathrm{N}^{\circ}$ 4-7.

Thompson, E. P. 1978 Poverty and Theory (Londres: Pantheon Books).

Thompson, E. P. 1964 The Making of the English Working Class (Londres: Pantheon Books). 
Tomich, Dale 1997 "World of Capital/Worlds of Labor: A Global Perspective" en Hall, John (ed.) Reworking Class (Ithaca / Londres: Cornell University Press).
Wallerstein, Immanuel 1989 (1974) The Modern World System (Nueva York: Academic Press). 3 Vols.

Wolpe, Harold 1973 The Articulation of Modes of Production (Londres: Routledge / Kegan Paul). 